\title{
Outcome of Induction and Associated Factors among Term and Post- Term Mothers Managed at Jimma University Specialized Hospital: A Two Years' Retrospective Analysis
}

\author{
Woubishet Girma ${ }^{1}$, Fitsum Tseadu ${ }^{1}$, Mirkuzie Wolde ${ }^{1}$
}

ABSTRACT

BACKGROUND: Induction of labor using oxytocin is a routine procedure in obstetrics used for vaginal delivery of gravid uterus. The purpose of this study was to analyze outcome of induction with oxytocin and associated factors among mothers who delivered at term and post-term in Jimma University Specialized Hospital, Southwest Ethiopia.

METHODS: A facility based cross-sectional study was conducted on records of 280 laboring mothers who delivered at term and post-term after induction with oxytocin from September $1^{\text {st }}, 2009$ to August 31 ${ }^{\text {st }}$, 2011. The data were extracted using checklist and analyzed using SPSS windows version 16.0. The level of significance to declare relationship between the dependent and independent variables was set at $p<0.05$.

RESULTS: Mean maximum oxytocin levels used until vaginal delivery and at time of diagnosis of failed induction were $55.0 \pm 29.8$ and $89.7 \pm 11.6$ miu/min respectively. Mean time elapsed from initiation of induction with oxytocin to vaginal delivery and till diagnosis of failed induction were 6:10 \pm 3:09 and 9:57 2:01 hours respectively. Failed induction was diagnosed in 21.4\% of the mothers. Primigravidity, unfavorable and intermediate Bishop Scores determined at admission were found to be predictors of failed induction.

CONCLUSION: High rate of failed induction and high level of oxytocin use were found. Preparation of the cervix before commencing induction in primigravid women is recommended to improve success of induction with the current protocol.

KEYWORDS: Oxytocin, Induction of labor, Failed induction, Successful induction, Bishop Score

DOI: http://dx.doi.org/10.4314/ejhs.v26i2.6

\section{INTRODUCTION}

Induction of labor refers to the iatrogenic stimulation of uterine contractions before the onset of spontaneous labor with or without ruptured membranes to accomplish vaginal delivery. Generally, induction of labor has merit as a therapeutic option when the benefits of expeditious delivery outweigh the risks of continuing the pregnancy (1-3).

The rate of labor induction varies by location and institution, and is increasing. In the United States and Canada, it is greater than $20 \%(1,4, \&$ 5). Although induction of labor with oxytocin is a daily practice at public and private health institutions, there is only one published study done in Ethiopia in 2004. According to this two years' retrospective case-series from two teaching hospitals in Addis Ababa, the prevalence of induction at term and post-term was $4 \%$ in both institutions (6).

Indications for induction of labor are not absolute but should take into account maternal and fetal conditions, gestational age, cervical status and other factors. Some of the maternal or fetal conditions that may be indications for induction of labor are abruptio placentae,

\footnotetext{
${ }^{1}$ Department of Gynecology and Obstetrics, Jimma University, Ethiopia

Corresponding Author: Woubshet Girma, Email: gwubdz@yahoo.com
} 
chorioamnionitis, fetal demise, pregnancy-induced hypertension, premature rupture of membranes (PROM), post-term pregnancy, maternal medical conditions (e.g., diabetes mellitus, renal disease, chronic pulmonary disease, chronic hypertension), fetal compromise (e.g., severe fetal growth restriction, iso-immunization), preeclampsia, and eclampsia. Labor may also be induced for logistic reasons like risk of precipitated labor, distance from hospital, or psychosocial indications (1-4).

Induction of labor should be used only when the benefits to the fetus or the mother of the baby outweigh those of the pregnancy continuing. The major risks associated with induction of labor include: increased cesarean delivery [C/D] (more on nulliparas) and operative vaginal delivery rate, chorioamnionitis, tachysystole with abnormal fetal heart rate patterns, uterine atony, increased cost, and rarely uterine rupture $(1-4,5)$.

Uterine activity and electronic fetal monitoring (EFM) are recommended for any gravida receiving uterotonic drugs (1-3). No consensus has been reached regarding the diagnosis of failed induction. A variety of end points have been suggested including cesarean delivery, not achieving a vaginal delivery within a specified time (such as within 12 or $24 \mathrm{hs}$ ), not achieving active labor within a specified time, or failure to achieve the active phase of labor (5).

The definition of failed induction should be derived from what is known about the pattern of labor progression in women undergoing induced labor who ultimately achieve vaginal delivery while maintaining a low incidence of adverse maternal and neonatal outcomes. The goal is to minimize the number of cesarean deliveries performed for failed induction in patients who are progressing slowly because they are still in the latent phase of labor. Once induced women enter active labor, progression should be comparable to progression in women with spontaneous active labor, or faster $(4,7)$.

Because of the risk of failed induction of labor, a variety of maternal and fetal factors as well as screening tests have been suggested to predict labor induction success. These include maternal factors [such as parity, height, weight, body mass index (BMI), maternal age, Bishop Score and its individual components], fetal factors (such as birth weight and gestational age), transvaginal ultrasound (TVUS) assessment of the cervix, and biochemical markers [including fetal fibronectin (fFN) and insulin-like growth factor binding protein-1 (IGFBP-1)] (1-3, 5 \& 8). The exact pharmacological half-life of oxytocin is controversial, but the available data suggest that a stable uterine response is obtained in $40-60$ minutes after initiating a constant-dose infusion. Therefore, the physiological half-life may be close to 10 minutes, since approximately four 'halflives' are required to obtain constant plasma levels (9).

Oxytocin protocols can be divided into two broad categories: high dose and low dose. This classification depends on the initial oxytocin dose, the amount of sequential increase in oxytocin dose, and the rate at which the dose is increased. Concerns about the safety and efficacy of the high-dose and low-dose protocols form the cornerstone of the debate regarding which protocol should be used in clinical practice (1-3).

Low dose protocols mimic endogenous maternal physiology and are associated with lower rates of uterine hyperstimulation. Low dose oxytocin is initiated at 0.5 to $1 \mathrm{miu}$ and increased by $1 \mathrm{miu} / \mathrm{min}$ at 40 - to 60 -minutes interval. Slightly higher doses beginning at 1 to $2 \mathrm{miu} / \mathrm{min}$ increased by 1 to $2 \mathrm{miu} / \mathrm{min}$, with shorter incremental time intervals of 15 to 30 minutes have also been recommended. High dose oxytocin regimens are often employed in active management of labor protocols. These regimens are largely used for labor augmentation, rather than for labor induction. Examples of these protocols start with an initial oxytocin dose of $6 \mathrm{miu} / \mathrm{min}$ increased by $6 \mathrm{miu} / \mathrm{min}$ at 20 minute intervals or start at $4 \mathrm{miu} / \mathrm{min}$ with $4 \mathrm{miu} / \mathrm{min}$ incremental increases (1-3). Although most protocols do not exceed $42 \mathrm{miu} / \mathrm{min}$, arbitrary maximum doses of oxytocin in various protocols have ranged from 20 to $40 \mathrm{miu} / \mathrm{min}$. Some practitioners have felt that a maximum dose is truly arbitrary and that the oxytocin should be administered until an adequate end-organ (uterine contraction) response is obtained $(1,3, \& 10)$.

Despite the controversies surrounding the use of induction with oxytocin to initiate labor and the absence of technological supports to evaluate likelihood of success in resource limited settings, there are few empirical evidences in relation to outcome of induction in Ethiopian hospitals. Thus, in this study, we aimed to answer the following 
two questions: What is the rate of failed induction among term and post-term women giving birth at Jimma University Specialized Hospital (JUSH)? What factors predict the outcome of induction in this group of mothers?

\section{METHODS AND MATERIALS}

The study was conducted in JUSH found in Jimma town $(352 \mathrm{~km}$ southwest of Addis Ababa). It is the only teaching and referral hospital in the southwestern part of the country. The hospital has a bed capacity of 450 of which 52 beds belong to the obstetric ward. The department gives 24 hours service of attending normal and abnormal labor including emergency cesarean section and laparotomy. During the study period, there were seven consultant gynecologists, 20 residents of four groups starting from $1^{\text {st }}$ year to $4^{\text {th }}$ year, varying numbers of medical interns, six midwives, and 20 clinical nurses. The hospital has a total of more than 750 staff (supportive and technical). It provides services for approximately 9000 inpatient and 80,000 outpatient attendances coming to the hospital from the catchment population of about $15,000,000$ a year.

A cross-sectional study was conducted by reviewing records of term and post-term deliveries from September $1^{\text {st }}, 2009$ to August 31 $1^{\text {st }}, 2011$. Hence, the source population was comprised of women who were admitted at term and post-term to the maternity and labor wards of the hospital during the study period. The study population included all women with term and post-term pregnancy who were admitted to the maternity and labor wards of the hospital and had induction with oxytocin during the study period.

Data were collected through review of medical records using a checklist which was prepared after reviewing different relevant literatures $(6,8,11,12 \& 13)$. Patient cards, labor ward log books, discharge log books, operation room log books, and medical interns' reporting log books were reviewed to collect the required data.
Data were collected by 10 trained medical interns and two first year residents under supervision of the principal investigator. All collected data were reviewed by the principal investigator for their completeness on daily basis.

Data were cleaned and entered into computer software to be analyzed using SPSS version 16.0. Results were presented using tables where frequencies, percentages and mean $\pm \mathrm{SD}$ were used whenever appropriate. Normally distributed continuous variables were compared using independent t-test. Bivariate analysis was carried out to determine associations of selected variables with the dependent variable and p-value of less than or equal to 0.25 was taken as a cut-off point to select candidate variables for the final multiple logistic regression models. Independent predictors were determined using adjusted odds ratio with 95\% confidence interval in multiple regression analysis at $\mathrm{p}$-value $<0.05$.

Prior to data collection, ethical clearance was obtained from Ethical Clearance Committee of the College of Public Health and Medical Sciences of Jimma University. Additionally, confidentiality of patient information was ensured by omitting their names and using card numbers instead.

In this study, outcome of induction was defined as successful if a woman delivered vaginally either spontaneously or by an instrument after induction with oxytocin. Failed if a woman delivered by $\mathrm{C} / \mathrm{S}$ due to failure to acquire either adequate uterine contraction $(\geq 3$ contractions or contractions lasting $\geq 40$ seconds in ten minutes period) or failed to show favorable cervical changes (reach at least $4 \mathrm{~cm}$ in dilatation and fully effaced) despite being on oxytocin drip for at least six hours or diagnosed as failed induction by the treating resident.

Table on labor induction protocol with oxytocin for all pregnant women in JUSH, using 6 units of oxytocin in $1000 \mathrm{ml}$ of IV fluids, start at $6 \mathrm{mu} / \mathrm{min}$, increasing every 20 minutes (Table 1). 
Table 1: Protocol of induction of labor with oxytocin for all gravid women of JUSH

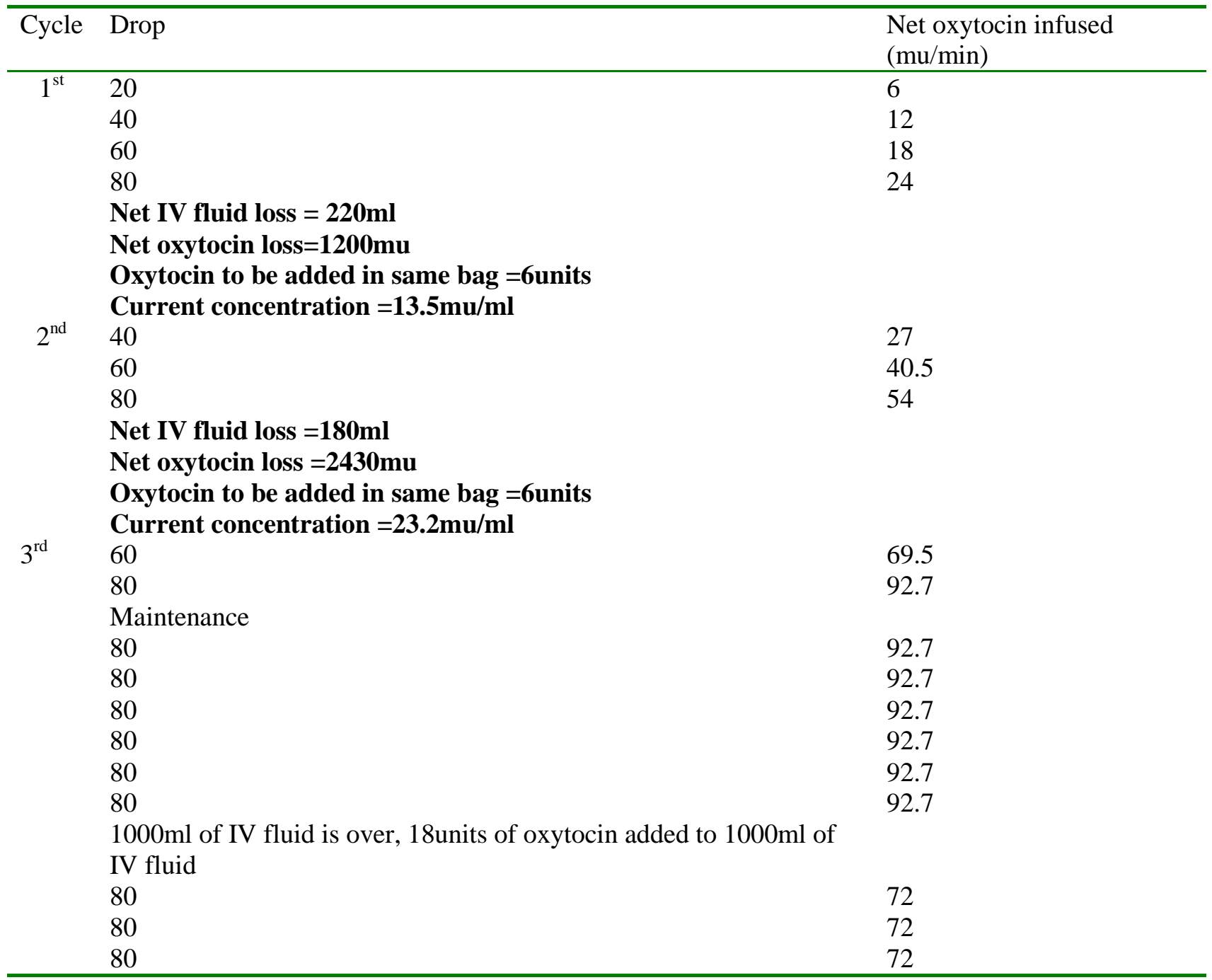

N.B. Interval between each dose is 20 minutes.

\section{RESULTS}

Of the total 354 records of mothers who delivered at term and post-term after being induced with oxytocin drip during the study period, 314 charts were retrieved making chart retrieval rate of $88.7 \%$. Fourteen charts were excluded from the analysis because of immediate development of non-reassuring fetal heart rate pattern (NRFHR) after initiation of oxytocin, 20 charts were also excluded from the study because of incompleteness. Analysis was based on the remaining 280 charts.

The age of the study subjects ranged from 1839 years and their mean age was $25.9(\mathrm{SD}=4.2)$ years. Of these, $175(62.5 \%)$ had term pregnancy, and multigravida mothers made up $152(54.3 \%$ ) of the study subjects. One hundred twenty $(45.4 \%)$ of the women had unfavorable Bishop Score at admission. Usage of vaginal misoprostol of 25 microgram $(\mathrm{mcg})$ for cervical ripening before initiation of induction with oxytocin was documented in $80(61.5 \%)$ of the women. The top three indications for induction in this study were PROM (36.6\%), hypertensive disorders of pregnancy $(34.3 \%)$ and post-term pregnancy (23.2\%). One hundred and eighty-two (65.0\%) mothers underwent induction of labor on emergency basis (Table 2). 
Table 2: Characteristics of pregnant mothers who underwent oxytocin induction in JUSH from September $1^{\text {st }}, 2009$ to August $31^{\text {st }}, 2011$.

\begin{tabular}{|c|c|c|}
\hline \multirow{2}{*}{$\begin{array}{l}\text { Variables } \\
\text { Age in years }(\mathrm{N}=280)\end{array}$} & & No. (\%) \\
\hline & $\begin{array}{c}\text { Mean } \pm \text { SD } \\
\leq 20 \\
21-25 \\
26-30 \\
31-35 \\
\geq 36\end{array}$ & $\begin{array}{c}25.9 \pm 4.2 \\
28(10) \\
121(43.2) \\
103(36.8) \\
22(7.9) \\
6(2.1)\end{array}$ \\
\hline Gestational Age $(\mathrm{N}=280)$ & $\begin{array}{c}\text { Term } \\
\text { Post-term }\end{array}$ & $\begin{array}{l}175(62.5) \\
105(37.5)\end{array}$ \\
\hline Gravidity $(\mathrm{N}=\mathbf{2 8 0})$ & $\begin{array}{c}\text { Gravida I } \\
\text { Gravida II } \\
\text { Gravida III } \\
\text { Gravida IV } \\
\text { Gravida V \& above }\end{array}$ & $\begin{array}{c}128(45.7) \\
78(27.9) \\
42(15.0) \\
12(4.3) \\
20(7.1)\end{array}$ \\
\hline Timing of induction $(\mathrm{N}=280)$ & $\begin{array}{c}\text { Planned } \\
\text { Emergency }\end{array}$ & $\begin{array}{c}98(35.0) \\
182(65.0)\end{array}$ \\
\hline Indication for induction $(\mathrm{N}=\mathbf{2 8 0})$ & $\begin{array}{c}\text { PROM } \\
\text { Hypertension } \\
\text { Post-term } \\
\text { No reason }\end{array}$ & $\begin{array}{c}102(36.4) \\
96(34.3) \\
65(23.2) \\
17(6.1)\end{array}$ \\
\hline Bishop Score status at time of admission $(\mathrm{N}=280)$ & $\begin{array}{c}\text { Unfavorable } \\
\text { Intermediate } \\
\text { Favorable }\end{array}$ & $\begin{array}{c}127(45.4) \\
68(24.3) \\
85(30.4)\end{array}$ \\
\hline $\begin{array}{l}\text { Usage of } 25 \mathrm{mcg} \text { of vaginal misoprostol to ripen } \\
\text { cervix }(\mathrm{N}=130)\end{array}$ & $\begin{array}{l}\text { Yes } \\
\text { No }\end{array}$ & $\begin{array}{l}80(61.5) \\
50(38.5)\end{array}$ \\
\hline
\end{tabular}

Outcome of induction with oxytocin: Of the 280 women, 154(55\%) had spontaneous vertex delivery, 96(34.2\%) underwent cesarean section and $30(10.7 \%)$ had instrumental delivery. Induction was successful in 184(65.7\%) of the study subjects, while $60(21.4 \%)$ of the mothers experienced failed induction. Nineteen $(6.8 \%)$ neonates were low birth weight $(<2500$ gram) and $248(88.6 \%)$ had normal birth weight (2500- 3999 gram) (Table 3). 
Table 3: Outcome of induction with oxytocin of pregnant mothers in JUSH from September $1^{\text {st }}, 2009$ to August $31^{\text {st }}, 2011$

\begin{tabular}{lll}
\hline Variable & & No. $(\boldsymbol{\%})$ \\
\hline Route of delivery $(\mathbf{N}=\mathbf{2 8 0})$ & Spontaneous vertex delivery & $154(55.0)$ \\
& Instrumental delivery & $30(10.7)$ \\
& C/S for NRFHR pattern & $25(8.9)$ \\
& C/S for CPD & $7(2.5)$ \\
& C/S for failed instrument & $4(1.4)$ \\
& C/S for failed induction & $60(21.4)$ \\
Neonatal weight $($ gram) $)(\mathbf{N = 2 8 0 )}$ & Mean \pm SD & $3139.86 \pm 496.013$ \\
& Range & $2000-5000$ \\
& $<2500$ & $19(6.8)$ \\
& $2500-2999$ & $80(28.6)$ \\
& $3000-3499$ & $106(37.9)$ \\
& $3500-3999$ & $62(22.1)$ \\
& $\geq 4000$ & $13(4.6)$ \\
\hline
\end{tabular}

Mean doses of oxytocin maintained in $\mathrm{miu} / \mathrm{min}$ for those with successful and failed inductions were $55.0 \pm 29.8 \& 89.7 \pm 11.6$, respectively. Range of level of oxytocin used varied from 6.0 to 93.0 and 48.0 to $95.0 \mathrm{miu} / \mathrm{min}$ for women with successful and failed inductions, respectively. Mean time elapsed from the start of induction with oxytocin to delivery in hours for cases with successful induction was $6.10 \pm 3.09$ hours, while it was as high as $9.57 \pm 2.01$ hours for those who had failed induction (Table 4).

Table 4: Dose of oxytocin maintained and time elapsed till delivery in JUSH from September $1^{\text {st }}, 2009$ to August $31^{\text {st }}, 2011$

\begin{tabular}{clll}
\hline Variable & & Frequency & \\
\cline { 3 - 4 } Dose of oxytocin maintained (miu/min) & & Successful induction & Failed induction \\
\hline & Median \pm SD & $55.0 \pm 29.8$ & $89.7 \pm 11.6$ \\
& Minimum & 54.0 & 6.0 \\
& Maximum & 93.0 & 93.0 \\
& Range & 87.0 & 48.0 \\
Time from start to delivery (hours) & Mean \pm SD & $6.10 \pm 3.09$ & 95.0 \\
& Median & 5.15 & 47.0 \\
& Minimum & 1.40 & $9.57 \pm 2.01$ \\
& Maximum & 16.00 & 9.00 \\
& Range & 14.60 & 6.00 \\
& & & 14.00 \\
\end{tabular}

Predictors of outcome of induction: Different socio-demographic and obstetric variables were entered in stepwise regression. In the initial model, mean age, gravidity, Bishop Score, timing of induction and neonatal weight demonstrated statistically significant association with the outcome variable at $\mathrm{p}<0.25$. However, only gravidity of the women and Bishop Score at admission persisted as independent predictors of outcome of induction with oxytocin in the multivariate model. Hence, primigravid women were 2.3 times more likely to have failed 
induction as compared to multigravid mothers $(\mathrm{AOR}=2.298,95 \%$ CI. 1.109,4.763). Those women who had unfavorable Bishop Score at admission were 5.3 times more likely to have failed induction as compared to those women with favorable Bishop score $(\mathrm{AOR}=5.275,95 \% \mathrm{CI}$.
2.005,13.878). Moreover, those women with intermediate Bishop Score at admission were 4.3 times more likely to have failed induction compared to those women with favorable Bishop Score at admission $(\mathrm{AOR}=4.287,95 \%$ CI. 1.432,12.834) (Table 5).

Table 5: Predictors of failed induction among pregnant mothers who underwent induction with oxytocin in JUSH from September $1^{\text {st }} 2009$ to August $31^{\text {st }} 2011$.

\begin{tabular}{|c|c|c|c|c|}
\hline Variable & $\begin{array}{l}\text { Successful } \\
(N=184)\end{array}$ & Failed $(\mathbf{N}=60)$ & $\begin{array}{l}\text { Crude OR } \\
(95 \% \text { CI })\end{array}$ & $\begin{array}{l}\text { Adjusted OR (95\% } \\
\text { CI) }\end{array}$ \\
\hline Age & & & $1.042(0.975,1.114)$ & $1.077(0.990,1.172)$ \\
\hline$\leq 20$ & $22(84.6 \%)$ & $4(15.4 \%)$ & $1^{*}$ & $1^{*}$ \\
\hline $21-25$ & $76(71 \%)$ & $31(29 \%)$ & $2.243(0.714,7.045)$ & $1.931(0.565,6.605)$ \\
\hline $26-30$ & $68(81.9 \%)$ & $15(18.1 \%)$ & $1.213(0.364,4.041)$ & $1.237(0.330,4.644)$ \\
\hline $31-35$ & $14(63.6 \%)$ & $8(36.4 \%)$ & $3.143(0.795,12.425)$ & $3.541(0.732,17.122)$ \\
\hline$\geq 36$ & $4(66.7 \%)$ & $2(33.3 \%)$ & $2.750(0.371,20.402)$ & $6.238(0.665,58.468)$ \\
\hline \multicolumn{5}{|l|}{ Gestational age } \\
\hline Term & $119(78.3 \%)$ & $33(21.7 \%)$ & $1.498(0.829,2.707)$ & $1.408(0.551,3.596)$ \\
\hline Post term & $65(70.7 \%)$ & $27(29.3 \%)$ & $1^{*}$ & $1 *$ \\
\hline \multicolumn{5}{|l|}{ Timing of induction } \\
\hline Planned & $62(72.1 \%)$ & $24(27.9 \%)$ & $1 *$ & $1^{*}$ \\
\hline Emergency & $122(77.2 \%)$ & $36(22.8 \%)$ & $0.762(0.418,1.389)$ & $0.802(0.316,2.032)$ \\
\hline \multicolumn{5}{|l|}{ Gravidity } \\
\hline Primigravida & $75(67.0 \%)$ & $37(33.0 \%)$ & $2.338(1.286,4.250)$ & $2.298(1.109,4.763) \dagger$ \\
\hline Multigravida & $109(82.6 \%)$ & $23(17.4 \%)$ & $1^{*}$ & $1^{*}$ \\
\hline \multicolumn{5}{|l|}{ PROM } \\
\hline Yes & $69(80.2 \%)$ & $17(19.8 \%)$ & $1^{*}$ & $1^{*}$ \\
\hline No & $115(72.8 \%)$ & $43(27.2 \%)$ & $1.518(0.804,2.866)$ & $0.787(0.338,1.830)$ \\
\hline \multicolumn{5}{|l|}{$\begin{array}{l}\text { Bishop Score status } \\
\text { at time of admission }\end{array}$} \\
\hline Unfavorable & $70(64.8 \%)$ & $38(35.2 \%)$ & $6.243(2.481,15.712)$ & $5.275(2.005,13.878) \dagger$ \\
\hline Intermediate & $45(73.8 \%)$ & $16(26.2 \%)$ & $4.089(1.488,11.234)$ & $4.287(1.432,12.834) \dagger$ \\
\hline Favorable & $69(92.0 \%)$ & $6(8.0 \%)$ & $1^{*}$ & $1^{*}$ \\
\hline Neonatal weight (gm) & $3059.29 \pm$ & $3214.33 \pm$ & & \\
\hline (Mean \pm SD) & 493.384 & 507.254 & & \\
\hline \multicolumn{5}{|l|}{$\begin{array}{l}\text { Weight of neonates } \\
\text { (gm) }\end{array}$} \\
\hline$<3000$ & $73(78.5 \%)$ & $20(21.5 \%)$ & $1 *$ & $1 *$ \\
\hline 3000- 3499 & $75(78.1 \%)$ & $21(21.9 \%)$ & $1.02(0.512,2.042)$ & $1.216(0.520,2.845)$ \\
\hline 3500- 3999 & $27(62.8 \%)$ & $16(37.2 \%)$ & $2.163(0.980,4.775)$ & $2.379(0.942,6.009)$ \\
\hline$\geq 4000$ & $9(75 \%)$ & $3(25 \%)$ & $1.217(0.301,4.920)$ & $2.136(0.407,11.212)$ \\
\hline
\end{tabular}

N.B. $1^{*}$ - reference, $\dagger$ statistically significant at P- Value $\leq 0.05$

\section{DISCUSSION}

The rate of failed induction was high at $21.4 \%$. Primigravidity and having admission time Bishop Scores of unfavorable and intermediate were found to be independent predictors of failed induction.

The rate of failed induction in this study is comparable to the rate in the study done in Addis
Ababa (28.4\%) (6). This is due to the similarity in the definition of failed induction time which is six to eight hours in both protocols which is not explained by their differences in the dose and escalation time interval used. It is also comparable to the failed induction rate of a study in Nigeria $(18 \%)$ (16). The failure rate is found to be higher than the rates of failed inductions of many other studies elsewhere: $15.2 \%$ in Australia (15), $4 \%$ of 
nulliparas in Birmingham (17), 2\% in Illinois (18), $6 \%$ in Iowa (12).

Reasons for this high rate of failure in our set up could be due to failure in maintaining the serum oxytocin concentration during change of infusion bag while the infusing bag is completed. Inappropriate storage of oxytocin which the principal investigator has witnessed himself during his practice as a resident can also be an other reason. Another explanation is the dose increment interval being every 20 minutes which is not in accordance with the currently accepted oxytocin pharmacokinetics which states a minimum of forty minutes is required to achieve steady serum level ( $9 \& 14)$.

Another possible reason for the high rate of failure could be the limited time that is used to define failed induction (6 to 8 hours). Compared to the Birmingham study, a minimum of 12 to 18 hours of membrane rupture and oxytocin administration before declaring failed induction is necessary (17).

Compared to the study done in Illinois, USA, a latent phase of as long as 18 hours during induction of labor in nulliparous women allows the majority of these women to achieve a vaginal delivery without being subject to a significantly increased risk of significant maternal or neonatal morbidity (18) The Australian study concluded that it would seem reasonable to continue an oxytocin infusion for at least ten hours in women undergoing induction who have yet to reach the active phase of labor $(\geq 4 \mathrm{~cm})$, and unclear benefit in continuing an induction beyond $12 \mathrm{~h}$ (15).

Primigravidity as an independent predictor for failed induction was also seen in most of the studies reviewed $(1-3,5,13,19)$. Admission time unfavorable Bishop Score and intermediate Bishop Score were shown to be predictors of failed induction in most of the studies reviewed $(1-3,5,8,13,20,21,22)$.

Mean oxytocin level maintained $(55.0 \pm 29.8$ $\mathrm{miu} / \mathrm{min}$ ) for those women with successful induction was higher than the mean dose of oxytocin used to attain adequate uterine contraction in Addis Ababa's study which is (33.6 $\pm 21.9 \mathrm{miu} / \mathrm{min}$ in primiparas and $17.2 \pm 11.4$ $\mathrm{miu} / \mathrm{min}$ in multiparas (6). This is due to the slight difference in the protocols used at these institutions: our protocol allows a maximum oxytocin dose of $95 \mathrm{miu} / \mathrm{ml}$, while the maximum dose attainable in Addis study is $73.4 \mathrm{miu} / \mathrm{min}$ for primigravidas. Of note, large doses of oxytocin were administered in the high-dose induction (range $=4.5$ to $117 \mathrm{mIU} / \mathrm{min}$ ) in the Iowa study (12).

It was also higher than the study done in Thomas Jefferson University, which suggested maximum dose of $16 \mathrm{mIU} / \mathrm{min}$. This is due to the protocol difference from this study; in the Thomas Jefferson University, a starting dose of $2 \mathrm{mIU} / \mathrm{min}$ with dilution of $10 \mathrm{mIU} / \mathrm{mL}$, increase by 2 $\mathrm{mIU} / \mathrm{min}$ every 45 minutes was used (14).

Mean dose of oxytocin maintained for those women with failed induction $(89.7 \pm 11.6 \mathrm{miu} / \mathrm{min})$ with a range of 48.0-95.0 $\mathrm{miu} / \mathrm{min}$ was higher than mean maximum level at diagnosis of failed induction $\left(60 \pm 16.2 \mathrm{miu}^{\prime} \mathrm{min}\right.$ for primiparous) used in the Addis' study (6). This can also be due to the difference in protocol.

Mean time elapsed from initiation of oxytocin to vaginal delivery $(6: 10 \pm 3: 09$ hours), with a range of 1:40-16:00 hours was comparable to the Addis' induction initiation to vaginal delivery time (7:10 $\pm 3: 25$ hours) (6). This can be explained by the fact that once women attain adequate uterine contraction, they follow the natural course of progress in active first stage of labor despite time interval.

This time is also comparable to the study done in Iowa, USA, which showed that with the high dose regimen, mean time from initiation to vaginal delivery was $8.5 \pm 0.3$ hours (12). This is explained by the effectiveness of high dose regimen protocol in shortening of labor duration which is shown in both studies.

Mean time gap between oxytocin initiation and diagnosis of failed induction was (9:57 $\pm 2: 01$ hours) with a range of 6:00-14:00 hours. It was comparable to the Addis' time (9:35 $\pm 3: 10$ hours) (6).

In conclusion, the rate of failed induction was found to be higher than most of the studies. Higher mean maximum doses of oxytocin were used. Time from start of induction with oxytocin to vaginal delivery was comparable to most of the studies with high dose oxytocin and time to diagnosis of failed induction was comparable to the study in Ethiopian. Primigravidity and having admission Bishop Scores of unfavorable and intermediate were found to be predictors for failed induction. Given the fact that only two non- 
modifiable risk factors for failure of induction with oxytocin were identified in this study, we recommend large scale studies to uncover other factors which could explain the high rate of induction failure. Revision of the protocol by the department is also recommended as duration of specific amount of dose and not high level of oxytocin would affect success. Additionally, time to define failed induction needs to be prolonged! Preparation of the cervix before commencing induction in primigravid women is recommended to improve success of induction with the current protocol. And, effects of various types of cervical ripening agents and quality of the oxytocin used and consistency of administration of drugs on the outcome of induction should also be studied. The fact that this is a retrospective type of data collection, and paucity of researches done in this subject in resource limited areas are the limitations of the study.

\section{ACKNOWLEDGEMENT}

The authors would like to thank Jimma University for funding this study.

\section{REFERENCES}

1. Leah R. Battista, Deborah A. Wing. Abnormal Labor and Induction of Labor. In: Steven G. Gabbe, Jennifer R. Niebyl, Joe Leigh Simpson (eds). Obstetrics: Normal and Problem Pregnancies, 5th ed. Philadelphia: Churchill Livingston elsevier, 2007: 322-343.

2. Labor induction. In: F. Gary Cunningham, Kenneth J. Leveno, Steven L. Bloom, John C. Hauth, Dwight J. Rouse, Catherine Y. Spong (eds). Williams Obstetrics. $23^{\text {rd }}$ edition. Stamford, Conn.: Appleton \& Lange, 2010.

3. American College of Obstetricians and Gynecologists. Induction of labor. ACOG practice bulletin number 10, November 1999: 514- 523.

4. Deborah A Wing. Induction of labor. Uptodate version 17.3. www.cdc.gov. September 2009.

5. Joan M. G. Crane. Factors Predicting Labor Induction Success: A Critical Analysis. Clinical obstetrics and gynecology. 2006 September; 49(3): 573-584

6. Berhan Y, Dwivedi AD. Currently used oxytocin regimen outcome measures at term
\& post-term I: Outcome indicators in relation to gravidity \& indication for induction. Ethiop Med J. 2007 Jul; 45(3):235-42.

7. Lin MG; Rouse DJ. What is a failed labor induction? Clin Obstet Gynecol. 2006 Sep; 49(3):585-93.

8. Knoche, A., Selzer, C. and Smolley, K. Methods of Stimulating the Onset of Labor: An Exploration of Maternal Satisfaction. The Journal of Midwifery \& Women's Health, July-August 2008; 53(4): 381-387.

9. Basson E, Odendaal HJ, Grové D. Oxytocin use in South Africa - a review. S Afr Med J. 2004; 94 (10): 839-45.

10. Smith JG; Merrill DC. Oxytocin for induction of labor. Clin Obstet Gynecol. 2006 Sep; 49(3):594-608.

11. BG Bako, JY Obed, IM Sanusi. Methods of Induction of Labor at the University Of Maiduguri Teaching Hospital, Maiduguri: A 4-Year Review. Nigerian Journal of Medicine. 2008, 17(2): 139-142.

12. Merrill DC, Zlatnik FJ. Randomized, doublemasked comparison of oxytocin dosage in induction and augmentation of labor. Obstet Gynecol 1999 Sep; 94(3):455-463.

13. Johnson DP; Davis NR; Brown AJ. Risk of cesarean delivery after induction at term in nulliparous women with an unfavorable cervix. Am J Obstet Gynecol 2003 Jun; 188(6):1565-9.

14. Hayes EJ, Weinstein L. Improving patient safety and uniformity of care by a standardized regimen for the use of oxytocin. Am J Obstet Gynecol 2008; 198:622.e1622.e7.

15. Beckmann M. Predicting a failed induction. Aust N Z J Obstet Gynaecol. 2007 Oct; 47(5):394-8.

16. Bissallah A, Ekele A, Jaiyeola A, Oyetunji A. Induction of labor at Usman Dan Fodiyo University Teaching Hospital, Sokoto. Trop J Obstet Gynaecol 2002; 19:74- 7.

17. Rouse DJ; Owen J; Hauth JC. Criteria for failed labor induction: prospective evaluation of a standardized protocol. Obstet Gynecol 2000 Nov;96(5 Pt 1):671-7

18. Simon CE; Grobman WA. When has an induction failed? Obstet Gynecol 2005 Apr; 105(4):705-9.

19. Ehrenthal DB, Jiang X, Strbino DM. Labor 
induction and the risk of a cesarean delivery among nulliparous women at term. Obstet Gynecol. 2010 Jul; 116(1): 35-42.

20. Osmundson SS, Ou-Yang RJ, Grobman WA. Elective induction compared with expectant management in nulliparous women with a favorable cervix. Obstet Gynecol. 2010 Sep; 116(3): 601-5.

21. Vrouenraets FP; Roumen FJ; Dehing CJ; van den Akker ES; Aarts MJ; Scheve EJ. Bishop score and risk of cesarean delivery after induction of labor in nulliparous women. Obstet Gynecol 2005 Apr; 105(4):690-7.

22. Ennen CS, Bofill JA, Magann EF, Bass JD, Chahan SP, Morrison JC. Risk factors for cesarean delivery in preterm, term and postterm patients undergoing induction of labor with an unfavorable cervix. Gynecol Obstet Inves. 2009; 67(2):113-7. 